\title{
MÃES DE CRIANÇAS COM DIFICULDADE ALIMENTAR SAO MAIS CONTROLADORAS E EXIGENTES: ESTUDO CASO- CONTROLE.
}

\section{Pôster}

Autores deste trabalho:

Rachel Helena Vieira Machado: Centro de Dificuldades Alimentares - Instituto PENSI

Priscila Maximino: Centro de Dificuldades Alimentares - Instituto PENSI

Raquel Ricci: Centro de Dificuldades Alimentares - Instituto PENSI

Cláudia de Cássia Ramos: Centro de Dificuldades Alimentares - Instituto PENSI

Maria Júlia Russo de Carvalho: Centro de Dificuldades Alimentares - Instituto PENSI

Mauro Fisberg: Centro de Dificuldades Alimentares - Instituto PENSI

Área do Trabalho: Nutrição

Data da submissão: 23/07/2018 às 13h51min

\section{Justificativa}

O cuidado responsivo e o tipo de estilo parental são sabidamente importantes moduladores do comportamento alimentar na infância, e há evidências na literatura de que famílias com queixas de dificuldades alimentares (DA) tendem a exercer práticas consideradas não responsivas, que podem exacerbar a queixa e/ou dificultar seu manejo.

\section{Objetivo(s)}

Comparar a prevalência de tipos de estilo parental em crianças com e sem presença de dificuldades alimentares.

\section{Método(s)}

Estudo observacional caso-controle realizado com 149 crianças com DA diagnosticada e grupo controle de 167 crianças sem DA ( $N$ total $=316)$, entre 8 e 94 meses de idade e de ambos os sexos. Os dados foram coletados a partir de entrevistas com as mães, e foram coletadas informações sociodemográficas, sobre o estilo parental e níveis de exigência e resposta (classificados segundo Hughes et al 2005). Utilizou-se os testes Qui-quadrado, GLM e teste T-Student, com nível de significância menor que 5\% e IC95\%, com poder amostral > 80\%.

\section{Resultado(s)}

O grupo com DA apresentou maior prevalência de sexo masculino $(64,4 \%$ vs $49,7 \%$; $p=0,009)$ e menor média de idade $(37,5$ vs 42,9 meses; $p=0,014)$ quando comparado ao controle. $O$ estilo parental mais prevalente no grupo de crianças com DA foi controlador $(34,8 \%)$, ao passo que o estilo indulgente foi mais frequente no grupo controle $(52,4 \%), p<0.001$. Houve efeito significante da presença de DA sobre os escores de exigência e resposta das mães, mesmo controlado para idade. As médias do escore de exigência são maiores no grupo de crianças com DA em relação ao 
controle (dif 0.41 pontos IC95\% 0.26, 0.55, p<0.0001).

\section{Conclusão (ões)}

O estilo parental controlador e com maiores escore de exigência quanto a alimentação foi associado à presença de dificuldade alimentar, mesmo controlado para idade.

Práticas parentais e perfis de demanda e resposta devem ser avaliados durante o acompanhamento da queixa alimentar, para subsidiar orientações assertivas e eficazes. 